\title{
Mathematical Concepts and Proofs from Nicole Oresme:
}

\section{Using the History of Calculus to Teach Mathematics}

\section{Condensed title: Math Concepts \& Proofs from Nicole Oresme}

Jeff Babb

REVISED SCED901

Department of Mathematics \& Statistics, University of Winnipeg, 515 Portage Avenue, Winnipeg, MB, Canada, R3B 2E9 (j.babb@uwinnipeg.ca)

Paper presented at The Seventh International History, Philosophy and Science Teaching Conference Winnipeg, MB, Canada August 1, 2003

\begin{abstract}
This paper examines the mathematical work of the French bishop, Nicole Oresme (c.1323-1382), and his contributions towards the development of the concept of graphing functions and approaches to investigating infinite series. The historical importance and pedagogical value of his work will be considered in the context of an undergraduate course on the history of calculus.

\section{Introduction}

The University of Winnipeg offers several sections per year of an undergraduate mathematics course entitled 32.2901/3 History of Calculus. The course gives an overview of the main ideas of calculus and surveys the development of these ideas and related mathematical concepts from ancient to modern times. It investigates issues such as the definition of calculus, how and when it developed, what problems inspired its creation, and how it changed the way mathematicians and others think about mathematical knowledge. Topics may range from early mathematical achievements (particularly those of Ancient Greece), to ideas of analytic geometry and calculus, to concepts of analytical rigor, transfinite numbers and nonstandard analysis. Lectures explore the historical efforts of mathematicians, philosophers, scientists, artists and mystics to understand 
and utilize the concepts of the infinitely small and the infinitely large. The course focuses on the evolution of ideas and discoveries leading to the work of Newton and Leibniz and on the subsequent extension and application of their ideas.

The audience for the course is quite mixed in terms of mathematical aptitude and interest. Roughly 60 percent of the students enroll in the course to try to obtain a mathematics credit without taking the regular offerings in calculus, discrete mathematics, linear algebra or statistics. About 20 percent are mathematics, statistics, physics or economics majors looking to gain a broader insight into the historical development of mathematics. About 10 percent are history and philosophy majors interested in the history of ideas. Many students also take one or more courses in the history of science that are offered through the history department.

In teaching the history of calculus, an effort is made to ensure that students learn about several aspects of mathematics and calculus, including proof concepts. Along with the historical component, it is required that students learn how to prove a number of theorems that have been chosen carefully for their relevance and clarity. Experience has determined that many of the proofs developed by the fourteenth century mathematical philosopher, Nicole Oresme, are ideally suited for presentation to students. This paper examines his mathematical work, particularly his contributions towards the development of the concept of graphing functions and approaches to investigating infinite series. The historical importance and pedagogical value of his work will be considered in the context of my undergraduate course on the history of calculus. WHO WAS NICOLE ORESME?

Nicole Oresme (c. 1323-1382) was born in Allemagne (west of Riez, in Normandy), France (The MacTutor History of Mathematics archive: Indexes of Biographies, 2003). According to Clagett (1981), he studied arts at the University of Paris in the 1340's with Jean Buridan, 
obtaining a masters in theology in 1355 or 1356 . Oresme became grand master of the College of Navarre in 1356. Starting about 1369, Oresme translated the works of Aristotle from Latin texts into French, with commentaries. He was appointed Bishop of Lisieux (in Normandy) in 1377 (Clagett, 1981).

Oresme was one of the top Medieval philosophers and wrote on mathematics, physics, economics, philosophy and theology. The Merton scholars of Oxford, England influenced his work in mathematics and physics. As noted by Baron (1969), between 1328 and 1350, the work of Thomas Bradwardine, William Heytesbury, Richard Swineshead and John Dumbleton, at Merton College, Oxford, laid the groundwork for further study of space and motion, by clarifying and formalizing key concepts, such as that of instantaneous velocity. As Cooke (1997) noted, important mathematical works by the Merton scholars include: Liber de proportionibus, written by Thomas Bradwardine in 1328, on proportions and Liber calculationum, written after 1328 by Richard Swineshead (also known as Richard Suiseth, Richard Suiset, or Calculator) on the latitude of forms.

The latitude of forms refers to the Medieval study of the intensity and variability of qualities. The term qualities refers to variables which could be quantified; as noted by Cohen (1985), a quality could be a physical variable such as displacement, speed, temperature, or heaviness, or a nonphysical variable such as love or grace.

As mentioned by Clagett (1968a), mathematical works by Oresme include: $D e$ configurationibus qualitatum et motuum, De proportionibus proportionum, Algorismus proportionum and Questiones super geometriam Euclidis. Oresme contributed greatly in three areas of mathematics: proportions, latitude of forms and infinite series. Each area will be examined in turn. 


\section{Proportions}

According to Boyer \& Merzbach (1991), Oresme extended the work of Bradwardine on proportions to include rules for any rational power which are equivalent to the modern laws of exponents (when restricted to rational powers): $\left(x^{a}\right)\left(x^{b}\right)=x^{a+b}$ and $\left(x^{a}\right)^{b}=x^{a b}$. He applied these rules to physical and geometric problems, introduced a special notation for fractional powers, and speculated that irrational powers are possible.

\section{Latitude of Forms}

Sometime between 1348 and 1362, Oresme introduced a geometrical approach to the latitude of forms. As noted by Boyer \& Merzbach (1991), Oresme was among the first to apply graphs to examine relationships between two variables; Casali was another. Oresme graphed the extension in time (longitude) of a quality along a horizontal line and the intensity of a quality (latitude) along a vertical line. As indicated by Suzuki (2002), Oresme assumed longitudinal lines to be in proportion, so that if one quality were twice as intense at one point as at another point, the longitudinal line at the first point would be twice as long at that at the second point. Boyer \& Merzbach (1991) also mention that Oresme provided a graphical proof of the mean speed rule (Merton rule) and discussed the three-dimensional representation of qualities with extension in both space and time.

Oresme was interested in the forms of qualities. When the quality under consideration is velocity, the terms used by Oresme correspond with those of modern physics as indicated in Table I. The various forms he considered are illustrated in Figure 1. As described by Baron (1969), Oresme represented a uniform quality by a rectangle and a uniformly difform quality by a triangle or trapezium. If the quality were difformly difform, Oresme used a curve or compound line for its summit line. 
Table I: Forms of Oresme

Form of Quality

Uniform

Uniformly difform

Difformly difform
Modern Physics Terminology

Constant velocity

Constant acceleration

Variable acceleration

\section{Insert Figure 1}

\section{MEAN SPEED RULE}

Hall (1962) notes that the study of the latitude of forms led Oresme to conclude that over a fixed extension, such as a period of time, the quantity of a uniformly varying quality is equivalent to that of a quality maintained at a constant level equal to the mean value of the uniformly varying quality. When the quality under consideration is velocity, this principle is known as the mean speed rule and may be stated as follows: An object, starting with an initial velocity and

accelerating uniformly over a specified time to reach some final velocity, travels a distance equal to that traversed by a second object moving for the same time at a constant speed equal to the average of the initial and final velocities of the first object.

Hall (1962) observes that the special application of this mean speed rule to velocity is usually called the Merton rule, because the Merton scholars of Oxford College derived it. Katz (1998) notes that William Heytesbury, who presented a proof based on an argument from symmetry, first proposed the rule in 1335. According to Clagett (1968b):

'... the invention of the mean speed theorem is one of the true glories of fourteenth century science'.

(Clagett 1968b, p.286)

Some readers may associate this rule with Galileo, who presented it as Theorem I, Proposition I, in the third chapter in the section entitled Natural Accelerated Motion, of his 1638 masterpiece 
Dialogue of The Two New Sciences (Galilei, 1638/1952). Hall (1962) observes that the mean speed rule was not applied to the problem of falling bodies until the sixteenth century. GRAPHICAL PROOF OF THE MEAN SPEED RULE As noted by Ford (2003), Oresme introduced the idea that constant acceleration (or uniform difform motion) could be portrayed by a right triangle oriented such that the right angle is rightmost. Refer to Figure 2. The left-most vertex corresponds to the initiation of a change in speed. Movement from left to right represents the passage of time, while the height of the triangle at a given point corresponds to the speed of an object under constant acceleration. By a similar argument, Oresme used a rectangle to represent constant speed (Katz, 1998). See Figure 2.

\section{Insert Figure 2}

Ford (2003) cautions the reader that, at the time of Oresme, a two-dimensional coordinate system to depict covariation between variables did not exist and advises that Oresme's right triangle be regarded as

‘... simply a visual, holistic expression of an intuition about constant acceleration'.

(Ford 2003, p.4)

Ford (2003) also argues that the acceptance of the triangle as away to represent motion was an important step to the later work by Galileo in which the parts of the right triangle and the mathematical relationships between them are used to study motion.

Oresme gave an eloquent graphical proof of the mean speed rule. See for example Clagett (1968a). For a history of calculus class, the proof may be adapted by introducing a coordinate system and presented as follows:

Label time along the horizontal axis and velocity along the vertical axis. Then uniform velocity corresponds to a horizontal line and constant acceleration corresponds to a line rising (or falling) at an angle. 
Consider an object, Object I, starting with an initial velocity $\mathrm{V}_{1}$ and accelerating uniformly for a specified time $\mathrm{T}$ until it attains final velocity $\mathrm{V}_{2}$. Suppose that a second object, Object II, travels at a constant velocity $\left(\mathrm{V}_{1}+\mathrm{V}_{2}\right) / 2$ for the same time $\mathrm{T}$. With reference to Figure 3 , the distances traversed by Object I and Object II are the areas of the trapezium ABFD and the rectangle ABEG, respectively. This claim can be justified by considering the units of measurement associated with distance, speed and time.

From Figure 3 it is evident that Area $($ trapezium $\mathrm{ABFD})=$ Area $($ rectangle $\mathrm{ABEG})+$ Area $($ triangle $\mathrm{EFH})$ - Area (triangle GDH)

Since, as Oresme assumed, the longitudinal (time) lines are in proportion to the intensity of the quality (velocity), the point $\mathrm{H}$ at which the horizontal line with height $\left(\mathrm{V}_{1}+\mathrm{V}_{2}\right) / 2$ intersects the rising line DF must have time coordinate $\mathrm{T} / 2$. Thus the two right triangles EFG and GDH are of equal area. Hence

Area $($ trapezium ABFD $)=$ Area $($ rectangle ABEG $)$, thereby proving the mean speed rule.

\section{QED}

\section{Insert Figure 3}

As Cooke (1997) observed, Oresme's proof of the mean speed rule represents the first recorded usage of one line to represent time, a perpendicular line to represent velocity, and the area under a curve to represent distance. Since distance is a linear concept, Oresme wrote extensively to justify the use of an area to represent a linear quantity. Boyer (1949) and Cooke (1997) noted that Oresme's analysis anticipates, by about 250 years, some aspects of the mechanics of Galileo. 
Oresme also proved the related result that the distance covered by an object under uniform acceleration is proportional to the square of time, which again anticipates aspects of the work of Galileo (Boyer \& Merzbach, 1991). In a history of calculus class, this argument may be presented as follows:

Consider a right triangle representing uniform acceleration.

The distance traveled is equal to the area of the triangle.

The area of the triangle is proportional to the product of its base and its height.

Both the base and the height are proportional to time.

QED

\section{Infinite series}

Oresme gave a clever proof of the divergence of harmonic series $\Sigma(\mathbf{1} / \mathbf{j})$. As Clagett (1981) noted, he discussed convergence and divergence conditions for geometric series and obtained the sums of several geometric series, including $\Sigma\left(\mathbf{1} / \mathbf{2}^{\mathbf{j}}\right), \Sigma\left(\mathbf{1} / \mathbf{3}^{\mathbf{j}}\right)$ and $\Sigma\left(\mathbf{a} / \mathbf{b}^{\mathbf{j}}\right)$. As well, according to Boyer \& Merzbach (1991), Oresme was able to sum the series $\Sigma\left(\mathbf{j} / \mathbf{2}^{\mathbf{j}}\right)$ and $\boldsymbol{\Sigma}\left(\mathbf{3} \mathbf{j} / \mathbf{4}^{\mathbf{j}}\right)$. (Note that in each series $\mathbf{j}$ is the index of summation and is understood to run from 1 to $\infty$ in increments of 1.) Table II shows how the work of Oresme may be incorporated into the overall discussion of infinite series in a history of calculus course. 
Table II: Discussion of Series in 32.2901/3 History of Calculus

\begin{tabular}{|c|c|}
\hline Individual(s) & Concepts Relating to Series \\
\hline \multirow[t]{2}{*}{ Zeno } & Paradoxes on motion \\
\hline & Distinction between potential and actual infinity \\
\hline \multirow[t]{2}{*}{ Pythagoreans } & Figurate geometry to sum first $\mathrm{n}$ positive integers \\
\hline & Figurate geometry to sum first $\mathrm{n}$ triangular numbers \\
\hline Eudoxus & Method of exhaustion \\
\hline \multirow[t]{2}{*}{ Archimedes } & Summation of the geometric series $\Sigma\left(1 / 4^{\mathbf{j}}\right)$ \\
\hline & Method of exhaustion \\
\hline \multirow[t]{4}{*}{ Oresme } & Convergence/divergence conditions for geometric series \\
\hline & Divergence of harmonic series $\Sigma(\mathbf{1} / \mathbf{j})$ \\
\hline & Summation of geometric series $\Sigma\left(\mathbf{1} / \mathbf{2}^{\mathbf{j}}\right)$ \\
\hline & Summation of series $\Sigma\left(\mathrm{j} / 2^{\mathrm{j}}\right)$ \\
\hline \multirow{2}{*}{ Cavalieri } & Infinitesimals \\
\hline & Principal of Cavalieri \\
\hline \multirow[t]{2}{*}{ Pascal } & Pascal triangle and binomial \\
\hline & Proof by mathematical induction (illustrate for sum of positive integers) \\
\hline \multirow[t]{2}{*}{ Wallis } & Book on series \\
\hline & Use of infinite series \\
\hline \multirow{2}{*}{ Newton } & Binomial series \\
\hline & Fluxions \\
\hline \multirow[t]{2}{*}{ Leibniz } & Summation of $\Sigma(\mathbf{1} /(\mathbf{j}(\mathbf{j}+\mathbf{1}) / \mathbf{2}))$ \\
\hline & Use of telescoping series \\
\hline $\begin{array}{l}\text { Gregory, Taylor } \\
\text { and Maclaurin }\end{array}$ & Taylor series \\
\hline \multirow[t]{2}{*}{ Euler } & Extensive use of infinite series \\
\hline & Infinite series for $\mathbf{e}^{\theta}, \sin \theta, \cos \theta$ \\
\hline Lagrange & $\begin{array}{l}\text { Attempt to formulate calculus starting with Taylor series, e.g. by defining } \\
\text { the derivatives } \mathbf{f}^{\prime}(\mathbf{x}), \mathbf{f}^{\prime \prime}(\mathbf{x}) \text {, etc. as the coefficients of } \mathbf{h}, \mathbf{h}^{2}, \mathbf{h}^{3} \text { in the Taylor } \\
\text { series expansion of } \mathbf{f}(\mathbf{x}+\mathbf{h}) \text { in terms of } \mathbf{h} \\
\text { Taylor series with a remainder }\end{array}$ \\
\hline \multirow[t]{3}{*}{ Cauchy } & Formal definition of limit \\
\hline & Formal definition of convergence and divergence of series \\
\hline & $\begin{array}{l}\text { Convergence/divergence tests: comparison test, root test, ratio test, } \\
\text { alternating series test }\end{array}$ \\
\hline Riemann & Formal definition of integral \\
\hline
\end{tabular}

\section{DIVERGENCE OF THE HARMONIC SERIES}

The harmonic series is the sum of the reciprocals of the positive integers. Examination of the partial sums in Table III and would suggest that the harmonic series grows very slowly. As 
noted by Clawson (1996), mathematicians thought for several centuries that the series converged. Table III: Growth of the Harmonic Series

\begin{tabular}{cc} 
No. of terms & Partial Sum \\
\hline 1 & 1.00 \\
2 & 1.50 \\
3 & 1.83 \\
4 & 2.08 \\
5 & 2.28 \\
6 & 2.45 \\
7 & 2.59 \\
8 & 2.72 \\
9 & 2.83 \\
10 & 2.93 \\
11 & 3.02 \\
12 & 3.10 \\
13 & 3.18 \\
14 & 3.25 \\
15 & 3.32 \\
16 & 3.38 \\
17 & 3.44 \\
18 & 3.50 \\
19 & 3.55 \\
20 & 3.60 \\
1000 & 7.49 \\
2000 & 8.18 \\
3000 & 8.58 \\
4000 & 8.87 \\
5000 & 9.09 \\
\hline
\end{tabular}

Oresme's clever proof of the divergence of the harmonic series was a remarkable accomplishment for the fourteenth century (Struik, 1987) and is mentioned in several calculus texts; e.g. Stewart (2003). In a history of calculus class, this proof may be presented as follows: Let $\mathbf{H}$ denote the harmonic series.

$$
H=1 / 1+1 / 2+1 / 3+1 / 4+1 / 5+1 / 6+1 / 7+1 / 8+1 / 9+\ldots
$$

Group the terms of $\mathbf{H}$ as follows: 


$$
H=1 / 1+[1 / 2]+[1 / 3+1 / 4]+[1 / 5+1 / 6+1 / 7+1 / 8]+[1 / 9+\ldots
$$

Define a new series I (which will be easier to analyze) by replacing each term in a bracketed grouping by the smallest term in that grouping.

$$
I=1 / 1+[1 / 2]+[1 / 4+1 / 4]+[1 / 8+1 / 8+1 / 8+1 / 8]+[1 / 16+\ldots
$$

Clearly $\mathbf{H}$ is not less than the new series $\mathbf{I}$, as the sum of terms in each bracketed grouping of $\mathbf{H}$ is not less than the sum of terms for the corresponding grouping of $\mathbf{I}$.

Observe that

$$
\begin{aligned}
I & =1 / 1+[1 / 2]+[2 / 4]+[4 / 8]+[8 / 16]+\ldots \\
& =1 / 1+[1 / 2]+[1 / 2]+[1 / 2]+[1 / 2]+\ldots
\end{aligned}
$$

which diverges.

But $\mathbf{H}$ is not less than $\mathbf{I}$, so $\mathbf{H}$ also diverges.

QED

\section{GEOMETRIC SERIES}

Today, it is well known that a geometric series with initial term $\mathbf{a}$ and common ratio $\mathbf{r}$

$$
\Sigma \mathbf{a r}^{\mathrm{j}-1}=\mathbf{a}+\operatorname{ar}+\operatorname{ar}^{2}+\ldots+\operatorname{ar}^{\mathrm{n}-1}+\ldots
$$

will converge to the sum $\mathbf{a} /(\mathbf{1}-\mathbf{r})$ if and only if $|\mathbf{r}|<\mathbf{1}$. Otherwise, the series diverges.

Oresme discussed convergence and divergence conditions for geometric series. In Questiones super geometriam Euclidis, Oresme

'... stated that when the infinite series is of the nature that to a given magnitude there are added "proportional parts to infinity" and the ratio $\mathbf{a} / \mathbf{b}$ determining the proportional parts is less than one, the series has a finite sum. But when $\mathbf{a}>\mathbf{b}$, "the total would be infinite"; that is, the series would be divergent'. (Clagett 1981, p.228). 
In this passage Oresme appears to be describing the general form of a geometric series and providing the usual rule for determining divergence and convergence. Clagett (1981) does not mention whether Oresme considered the divergent case when $\mathbf{a}=\mathbf{b}$.

Oresme also obtained the sums of several geometric series through a geometric approach, which he introduced. In a history of calculus class, his method may be applied to sum the geometric series with common ratio $\mathbf{1 / 2}$ and initial term $\mathbf{1}$, as follows:

Let $\mathbf{G}$ denote the geometric series with common ratio $\mathbf{1 / 2}$ and initial term $\mathbf{1}$.

$$
G=1+1 / 2+1 / 4+1 / 8+\ldots+1 / 2^{n-1}+\ldots
$$

Oresme argued geometrically to prove that $\mathbf{G}=\mathbf{2}$.

In Figure 4, square ABCD and square EFGH each have sides of length 1 and hence area 1.

Square ABCD has been subdivided by successive halving into an infinite sequence of rectangles with respective areas of $1 / 2,1 / 4,1 / 8, \ldots, 1 / 2^{n-1}, \ldots$

\section{Insert Figure 4}

Summing the areas of the rectangles of square $\mathbf{A B C D}$ from left to right yields

$$
1 / 2+1 / 4+1 / 8+\ldots+1 / 2^{n-1}+\ldots=1
$$

since the areas of the rectangles must add to the area of square $\mathbf{A B C D}$.

Adding the area of square $\mathbf{E F G H}$ to the area of square $\mathbf{A B C D}$ yields

$$
1+1 / 2+1 / 4+1 / 8+\ldots+1 / 2^{n-1}+\ldots=1+1=2
$$

At this point students are reminded that, as noted by Grattan-Guinness (1997), the series relates to one form of Zeno's paradox of the dichotomy, which they would have encountered earlier in the course (see Table 2 above).

SUMMATION OF THE SERIES $\Sigma\left(\mathbf{j} / \mathbf{2}^{\mathbf{j}}\right)$ 
Consider the series

$$
B=\Sigma\left(j / 2^{j}\right)=1 / 2+2 / 4+3 / 8+4 / 16+\ldots+n / 2^{n}+\ldots
$$

Oresme gave a clever geometric proof that $\mathbf{B}=\mathbf{2}$. His argument may be presented in a history of calculus class as follows:

Refer to Figure 5 in which the vertical height of each layer of rectangles is $\mathbf{1}$ and the width of the large base rectangle in the first layer is $\mathbf{1}$.

The area of the large base rectangle is $\mathbf{1}$.

The large rectangle in the first layer has been subdivided by successive halving into an infinite sequence of rectangles with respective areas of $1 / 2,1 / 4,1 / 8, \ldots, 1 / 2^{n}, \ldots$

The area of the first layer of rectangles is $\mathbf{1}$.

The right half of the first layer has been duplicated and placed in the second layer immediately above itself. It consists of an infinite sequence of rectangles with respective areas of

$1 / 4,1 / 8,1 / 16, \ldots 1 / 2^{n}, \ldots$

The area of the second layer of rectangles is clearly $\mathbf{1 / 2}$.

The right half of the second layer has been duplicated and placed in the third layer immediately above itself. It consists of an infinite sequence of rectangles with respective areas of

$1 / 8,1 / 16, \ldots 1 / 2^{n}, \ldots$

The area of the third layer of rectangles is clearly $\mathbf{1 / 4}$.

And so on.

The area of the tower of rectangles may be found in two ways by summing horizontally and by summing vertically.

Summing areas of the layers of rectangles horizontally yields:

Area of tower $=1+1 / 2+1 / 4+1 / 8+\ldots+1 / 2^{n}+\ldots$ 
This is the series $\mathbf{G}$ which sums to $\mathbf{2}$, as shown previously.

Summing areas by vertical columns of rectangles yields:

$$
\text { Area of tower }=1 / 2+2 / 4+3 / 8+\ldots+n / 2^{n}+\ldots
$$

As the area must be the same both ways, it follows that

$$
B=1 / 2+2 / 4+3 / 8+\ldots+n / 2^{n}+\ldots=2
$$

\section{Insert Figure 5}

Stillwell (1989) notes that this construction by Oresme may be the first example of a figure that is infinite in extent but has finite content, a phenomenon later investigated by Torricelli when studying a hyperbolic solid of revolution. Baron (1969), Edwards (1979) and Katz (1998) have good discussions of Oresme's summation of this series.

\section{Conclusion}

The mathematical work of the fourteenth century mathematical philosopher Nicole Oresme provides a rich source of relevant theorems and eloquent proofs for use in an undergraduate course on the history of calculus. Experience at the University of Winnipeg has shown that it particularly fruitful to discuss his investigations into the latitude of forms, his proof of the divergence of the harmonic series, and his geometric summations of infinite series. 


\section{References}

Baron, M.E.: 1969, The Origins of the Infinitesimal Calculus (reprinted in 1987), Dover

Publications, New York.

Boyer, C.B.: 1949, The History of Calculus and Its Conceptual Development (reprinted in 1959), Dover Publications, New York.

Boyer, C.B. \& Merzbach, U.C.: 1991, A History of Mathematics (second edition), John Wiley and Sons, New York.

Clagett, M.: 1968a, Nicole Oresme and the Medieval Geometry of Qualities and Motions: A Treatise on the Uniformity and Difformity of Intensities Known as Tractatus de confurationibus qualitatum et motuum, The University of Wisconsin Press, Wisconsin.

Clagett, M.: 1968b, 'Some Novel Trends in the Science of the Fourteenth Century', in Studies in Medieval Physics and Mathematics, Vaviorum Reprints, London, 1979, 277-303.

Clagett, M.: 1979, Studies in Medieval Physics and Mathematics, Vaviorum Reprints, London. Clagett, M.: 1981, 'Oresme, Nicole' in C.C. Gillespie (ed.), Dictionary of Scientific Biography, Vol 9, Charles Scribner's Sons, New York 223-230.

Clawson, C.C.: 1996, Mathematical Mysteries: The Beauty and Magic of Numbers, Perseus Books, Cambridge, MA.

Cohen, I.B.: 1985, The Birth of a New Physics: Revised and Updated, Norton, New York. Cooke, R.: 1997, The History of Mathematics: A Brief Course, John Wiley \& Sons, New York. Edwards, C.H.: 1979, The Historical Development of the Calculus (reprinted in 1982), SpringerVerlag, New York.

Ford, M.: 2003, 'Representing and Meaning in History and in Classrooms: Developing Symbols and Conceptual Organizations of Free-Fall Motion', Science \& Education, 12(1), 1-25. 
Galilei, G.: 1638/1952, Dialogue of The Two New Sciences, Encyclopaedia Britannica, Chicago. Grattan-Guinness, I: 1997, The Fontana History of the Mathematical Sciences: The Rainbow of Mathematics, Fontana, London.

Hall, M.B.: 1962, The Scientific Renaissance 1450-1630 (reprinted in 1994), Dover Publications, New York.

Katz, V. J.: 1998, A History of Mathematics: An Introduction (second edition), Addison Wesley Longham, New York.

The MacTutor History of Mathematics archive: Indexes of Biographies: 2003. Nicole d' Oresme, 29 Sept. 2003, School of Mathematics and Statistics, University of St. Andrews, Scotland, http://www-history.mcs.st-andrews.ac.uk/history/BiogIndex.html.

Stewart, J.: 2003, Single Variable Calculus, (fifth edition), Thomson Brooks Cole, Toronto, ON. Stillwell, J.: 1989, Mathematics and Its History, Springer-Verlag, New York.

Struik, D.J.: 1987, A Concise History of Mathematics (fourth revised edition), Dover Publications, New York.

Suzuki, J.: 2002, A History of Mathematics, Prentice Hall, Upper Saddle River, NJ.

Zippin, L.: 1962, Uses of Infinity, (reprinted in 2000) by Dover Publications, New York. 


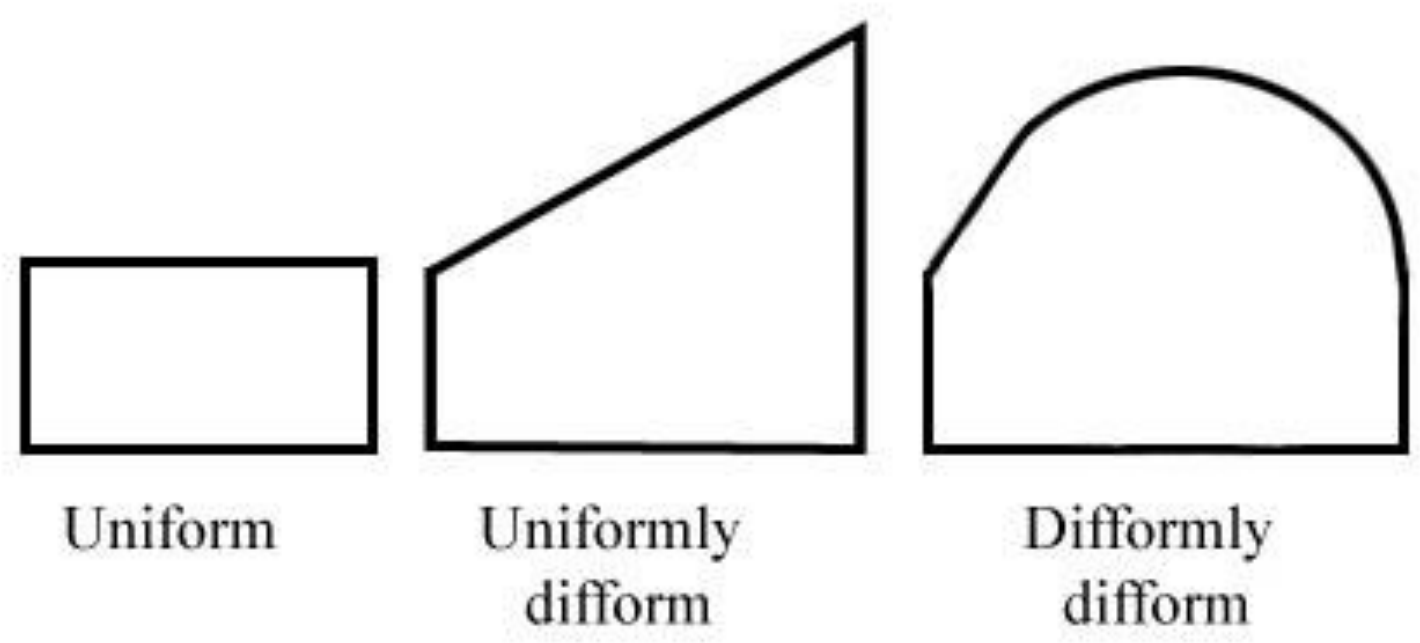

Fig. 1: Forms of Oresme 

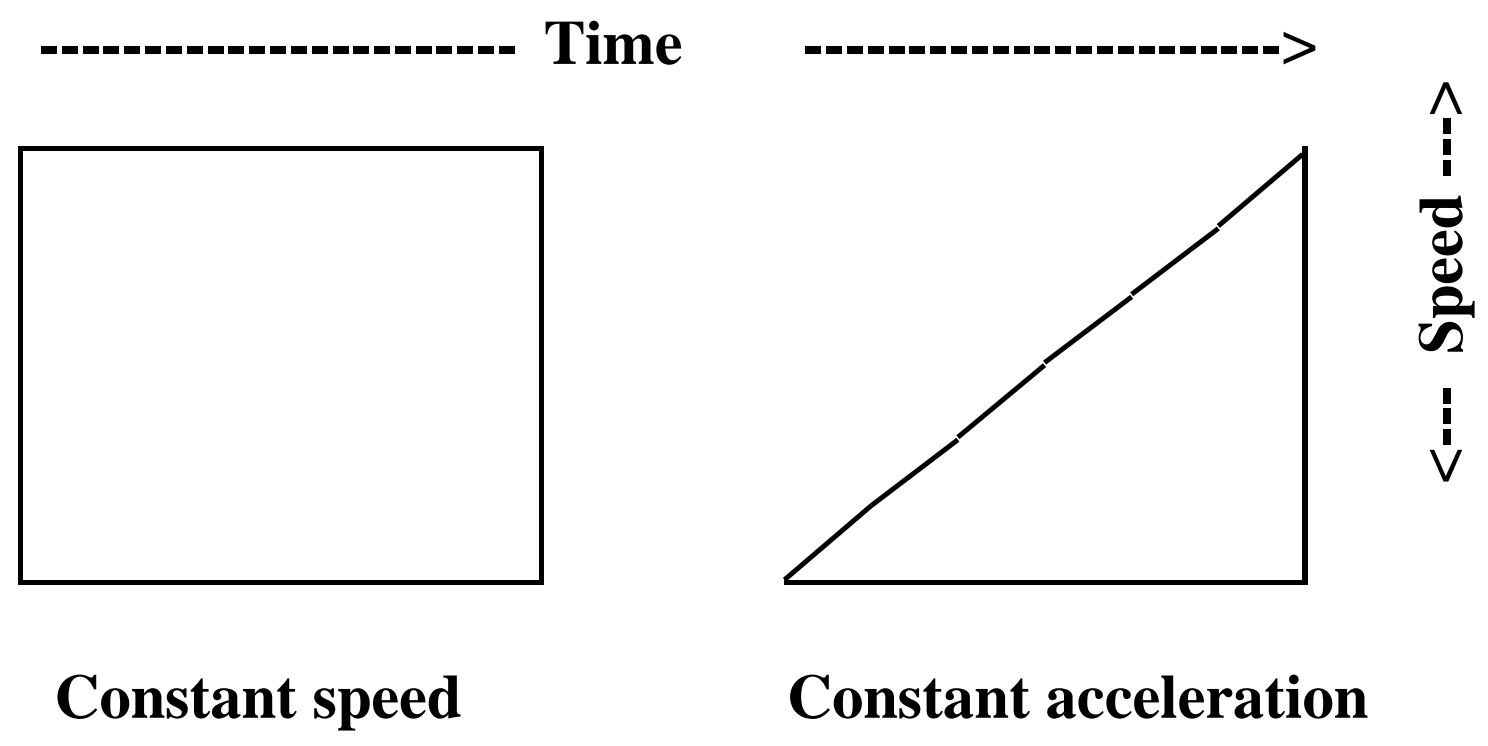

Fig. 2: Oresme's representation of constant speed and constant acceleration 


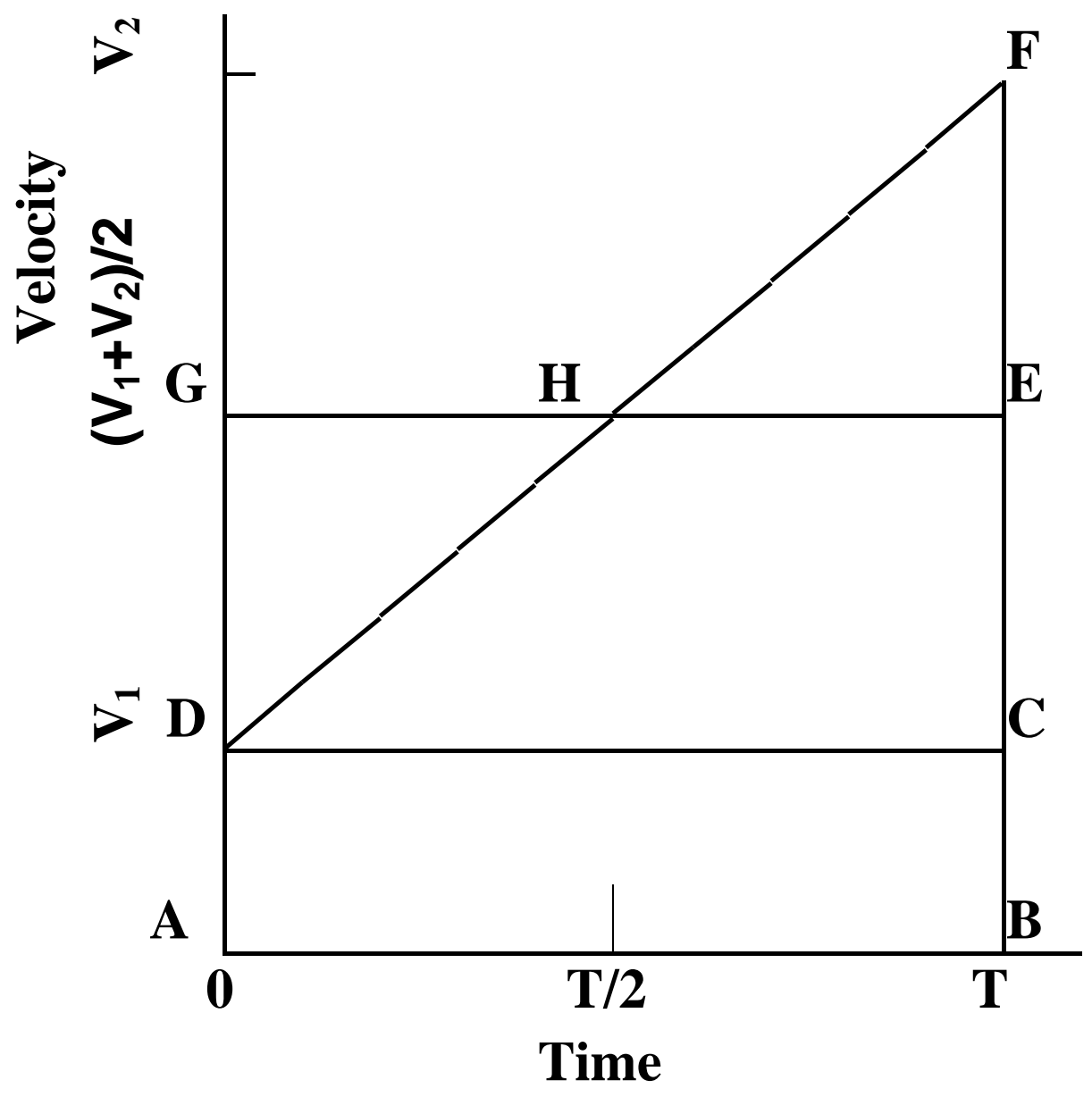

Fig. 3: Graphical Proof of the Mean Speed Rule 

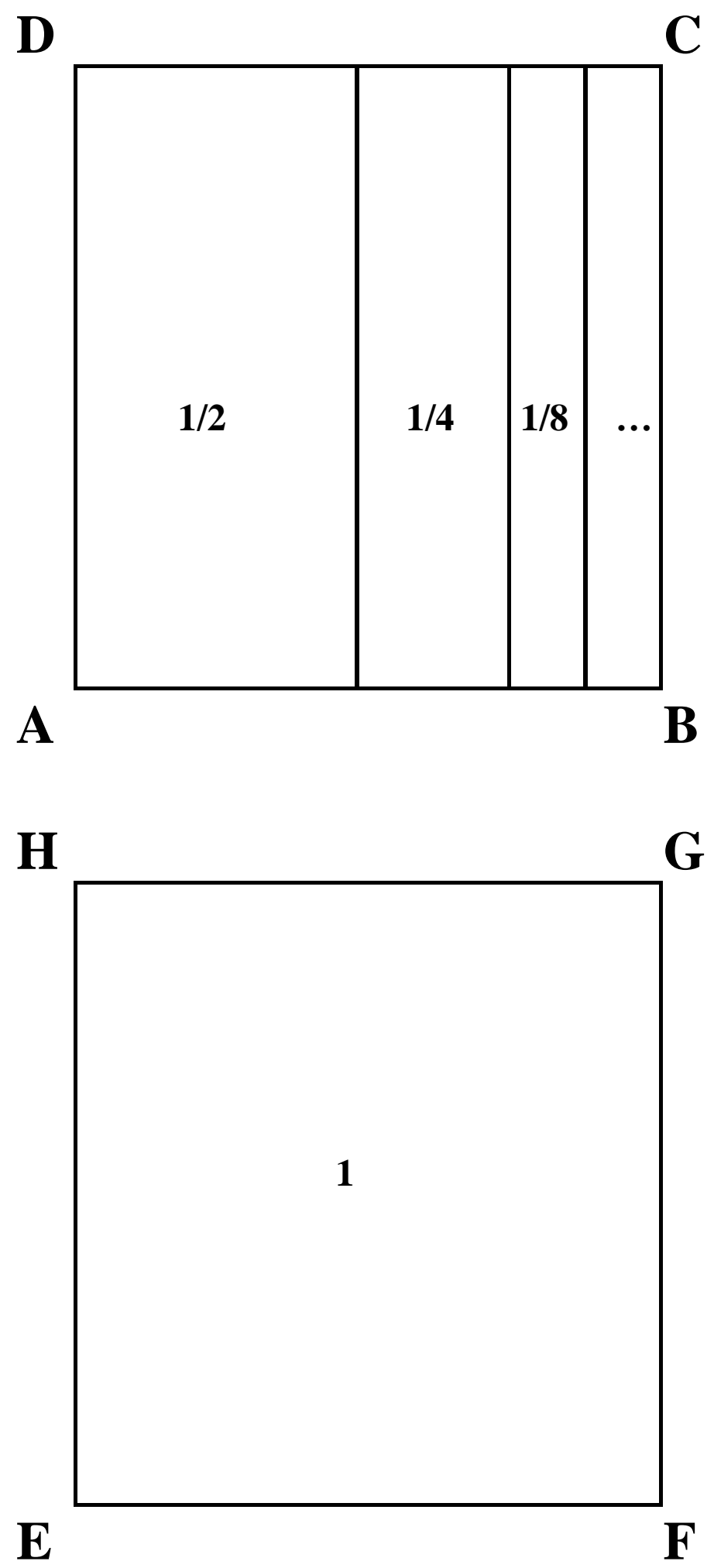

Fig. 4. Summation of a Geometric Series 


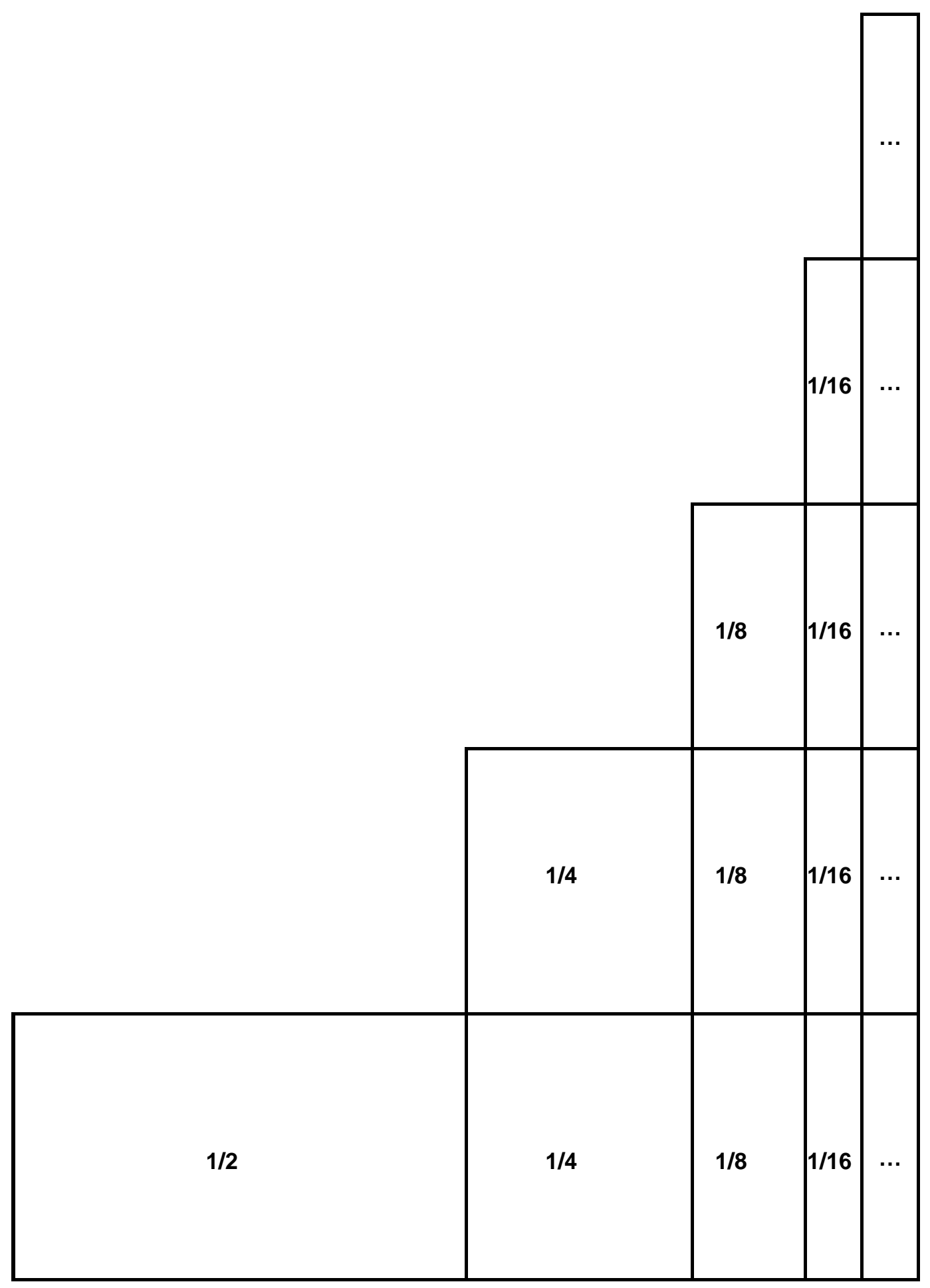

Fig. 5. Summation of a Series $\Sigma\left(\mathbf{j} / 2^{\mathbf{j}}\right)$ 